International Journal of Engineering \& Technology, $7(2.23)(2018) 323-327$
International Journal of Engineering \& Technology
Website: $w w w . s c i e n c e p u b c o . c o m / i n d e x . p h p / I J E T$
Research paper

\title{
Travel demand estimation through corridor level analysis for hyderabad metro rail
}

\author{
Prashanth Shekar Lokku ${ }^{1}$, Csrk Prasad ${ }^{1}$ \\ ${ }^{1}$ National Institute of Technology Warangal, India \\ *Corresponding author E-mail: lps.lokku@gmail.com
}

\begin{abstract}
Urbanisation around the world is occurring in a rapid manner. Due to which peoples' lives are in measurable situation like damaging the environment via increase in usage of private vehicles. In this line, transportation engineering plays a vital role in terms of sustainable development. Sustainability is the term used for balancing the three main components like social, environment and economic; not to trouble much of natural resources so as to preserve them for the future generations. To address the problems related to the transportation like traffic congestion, increase in pollution etc., Mass Rapid Transit System (MRTS) is the best alternative. To plan the MRTS in urban areas, it is necessary to estimate the travel demand, so as to fulfil the financial viability criteria.Corridor level analysis is performed to estimate the travel demand for Hyderabad Metro Rail, India. Multinomial Logit model (ULOGIT) is used to obtain the probability of MRT desired upon various modes. The results revealed that there would be adequate demand for the proposed MRT if the MRT could have double fare than that of bus fare and has half of the travel time to that of the current bus.
\end{abstract}

Keywords: Sustainability; Travel Demand; Ulogit; Transit Patronage.

\section{Introduction}

The growth of urban areas in developing countries increases exponentially in terms of population and vehicles, hindering the healthy economic development of an area. Migration of people from rural areas to cities in developing countries is the effect of swift urbanization and industrialization, causinginadequate public transportation facilities in most of the cities. Factors such asregularity, reliability, ease and suitability force commuters to prefer personalized vehicles or paratransit, depending upon their affordability. Easy availability of finance coupled with high disposable income is increasing the vehicle ownership in cities.

The mobility requirements of all sections of society leads to mixed traffic conditions consisting of travel modes such as pedestrians, cycles, auto rickshaws, buses, cars, vans, cycle rickshaws, animal drawn vehicles etc. and the demand for travel is increasing day by day. On the supply side, the urban road capacity which is being shared by moving vehicles and encroachers in most of the developed countries can be tried practically on case to case basis to ease the traffic congestion. Traffic congestion can be curbed to some extent by making mass transport facilities attractive to all class of commuters.

Urban traffic congestion must be understood in the context of city dynamics and growth [16]. Traffic congestion ismainly the outcome of unplanned economic development, employment, housing and lack of policy measures in regulating the traffic and land use. For example, Hyderabad vehicle composition in percentage is personalized vehicles-94.39percentage, IPT-5.23percentage and public transport-0.38percentage. There has been little progress in development of mass urban transit system in the country. In the case of public transport bus system, the fleet size increase has been almost nil for many cities and suburban rail transit system exists in just four out of thirty-five Indian cities with population in excess of one million. The share of public transport in Hyderabad is $45 \%$ with population of 9.3 million. If the private modes are allowedto continue, the entire system will get choked up with capacity vehicles occupying more road spaces per person trip. As per the recommendations, Hyderabad city should have $70 \%$ share by public transport as against $45 \%$ even for the present population level. Keeping in view the requirements and the demand for the route space it is absolutely necessary to reorient the mode of travel in Hyderabad and encourage high occupancy vehicles for carrying more passengers per vehicle requiring less space for person trips. Hence, travel demandestimation is vital and the most important phase in planning of Mass Transportation System [3].

\section{Literature review}

Conventional transport demand models are reviewed in the present study. Generally,in conventional transport modelling,the study area is divided into zones to consider the generators and attractors of trips.The modelling process in steps of four sub-modelsis as follows [1], [2], [4], [5], [6], [2], [2]:

- Generation of Trip: The zonal data is used to generate number of trips "generated from" and "attracted to" each zone.

- Distribution of Trip:Here the "origin-destination matrix"(i.e., the number of trips from each zone to each zone) is formed. Gravity type model is usually preferred.

- Modal split: Mode choice made by each traveler is replicated.

- Assignment: Route tracked by each trip is demonstrated. The output includes link flows and modified measure of costs of travelling between each pair of zones.

Economic approach for determining demand is also found in literature [20-21]. In this view author simplified the procedure for small 
scale projects. Data collection techniques are also important in planning [7]-the most efficient and relatively less complex procedures are adopted based on the review carried out. Mode choice models are vastly mentioned and reviewed [10], [12], [13], [14], [18] and best possible models were adopted as discussed in following sections.

In India, MRT studies are carried out [1], [2], [8], [9], [15] in Delhi, Mumbai, Chennai and Hyderabad as well.

\section{Methodology}

As city expands to accommodate the growth in population and activities, the spatial separation between the population and employment locations increase; increasing needs for travel modes are felt. The daily needs of residents for work, education, business, shopping and recreation create enormous demand on transport system. In order to understand the travel behaviour for transportation planning and management, the patronageis to be estimated. Once the patronage is estimated, suitable planning models could be developed and relevant management policies can be adopted to tackle many of urban problems. The patronage was estimated in the past by the urban transportation planning (UTP), which was eventually a four-step conventional planning process. This analysis employs huge amount of data, consuming large amount of time, the process gives the demand directly by way of the desire line diagram for a specified purpose for each route serving a particular land use. However, this method consumes enormous time for data collection and data analysis.

In view of above difficulties encountered in the UTP analysis, it is necessary to estimate the transit demand utilizing small amount of data by (a) alighting counts to get an appropriate outcome and (b) passenger interview surveys to capture the preference on introducing new mode of public transport i.e., metro rail. The present study aimed to utilize these data sources for the present selected corridor analysis.

\subsection{Application of LOGIT model for mode choice}

Logit model belonging to the group of qualitative choice model is selected for mode wise corridor level O-D estimation. In any choice situation, the person making the trip has two or more different alternatives among which a person has to choose depending upon the disutility function. Hence, the calibration of the model is done based on the values of the coefficients of disutility function developed from the observed data. For this, likelihood maximization technique is adopted to calibrate the logit model. In general, the calibration is carried out in three stages namely; data preparation, variables selection and estimation of the parameters. The logit model is calibrated to determine the present mode share.

Identification of choice set

In analysis, a qualitative choice situation is defined wherethe decision maker meets the following criteria [11]

- Limited alternatives in the choice set

- Necessity of choosing one alternative at a time exclusively

- Comprehensive set of alternatives

- Functional form of disutility function

Every traveller, intending to travel chooses the mode whose characteristics like time, cost, speed, comfort etc., are weighed by his or her importance to him, producing the most favourable combination (least disutility) relative to other modes. In support of this hypothesis the following assumption are made:

- Rationality: Rationality means that a traveler would behave in a manner of the classical economic man.

- Limited resources: for a meaningful choice problem, it is necessary to assume that the economical resources available to the traveler are limited i.e., his income is fixed.

- Perfect knowledge: it is assumed that the traveler is aware of the characteristics of all the modes.

The functional form of disutility functioning general is
$\mathrm{V}_{\mathrm{in}}=\beta_{\mathrm{io}}+\sum_{\mathrm{k}} \beta_{\mathrm{ik}} \mathrm{X}_{\mathrm{ik}}\left(\lambda_{\mathrm{k}}, \mu_{\mathrm{k}}\right)$

Where $\lambda_{\mathrm{k}}$ and $\mu_{\mathrm{k}}$ are transformation parameters of variables $\mathrm{X}, \mathrm{B}$ is vector of model parameters and $X$ is vector of independent variable Setting the vector $\mu=\mu_{1}+\ldots \ldots \ldots \mu_{\mathrm{k}}=0$ and $\lambda=$

$\lambda_{1} \lambda_{2} \ldots \ldots \ldots . \lambda_{\mathrm{k}}=0$

The disutility expression would be

$V_{\text {in }}=\beta_{\text {i o }}+\prod_{k} \beta_{i k} X_{i k}$

If $\lambda=\lambda_{1}+\lambda_{2}+\ldots \ldots \ldots \lambda_{k}=1$

This utility function which is linear in modelling parameters is used in the present work.

From the utility equations, the road users who are likely to shift to MRT is assessed.

\section{Study area}

The study area for the present research is Hyderabad. The study corridor selected is fromMiyapur to Nampally. This corridor comprisesof 17 proposed MRTS stations as given in Fig. 1. This is along the NH-9 passing through center of the city and connecting important activity centers, such as Kukatpally, Balanagar, Ameerpet, Punjagutta and Nampally. Kukatpallyis a well knowndeveloped residential zone, Balanagar isoccupiedby industries, whereasAmeerpet, Punjagutta and Nampally are significantly commercially developedcenters. This corridor has some important feeder routes across connection road at various places.
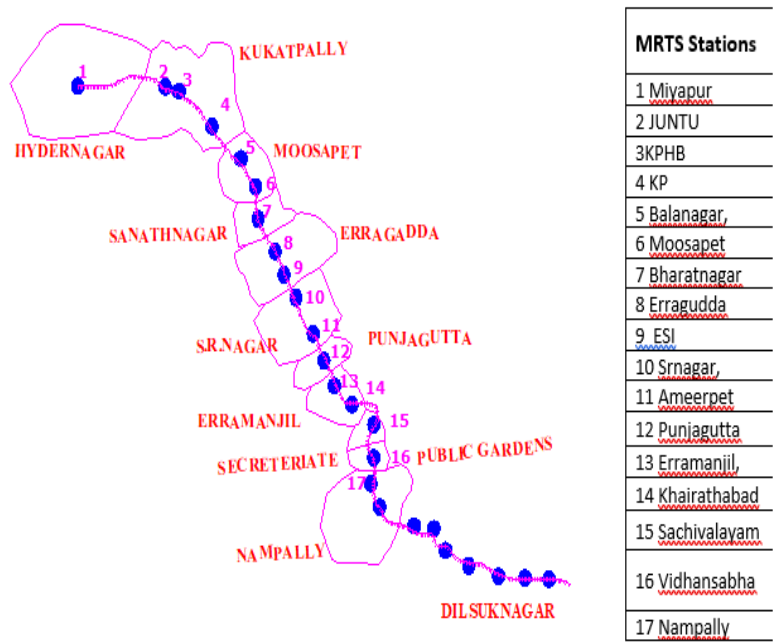

Fig. 1: MRTS Corridor with Stations.

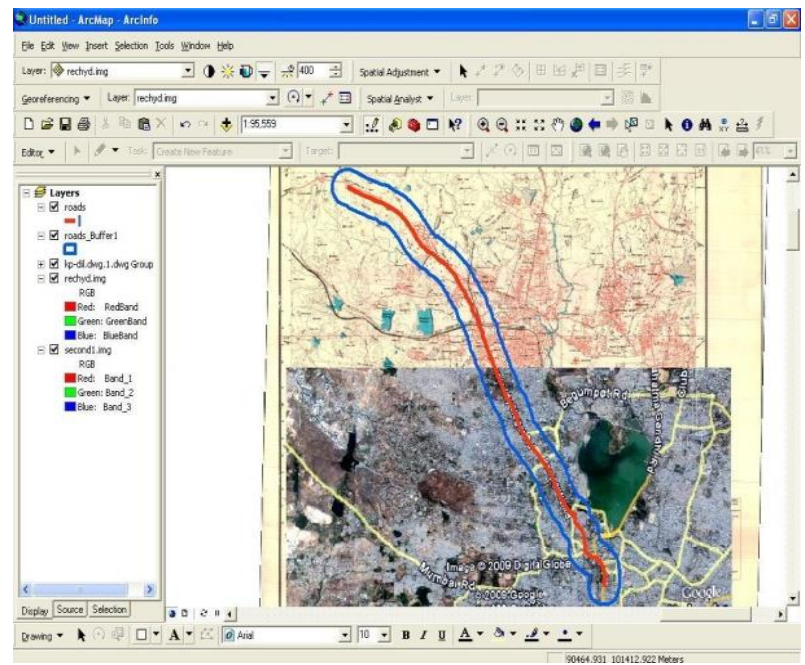

Fig.2: Hyderabad TOPO Sheet with Identified Corridor Boundaries. 


\section{Data and analysis}

The questionnaire was prepared for the bus stop passenger, twowheeler and car passengers. The questions are related to the following basic data [19].

1) Travel related data of passenger covering Origin, Destination address and purpose.

2) Trip data of passenger covering ingress distance, egress distance and waiting time for the bus.

3) Socio economic characteristics of passengers covering income, vehicle ownership.

4) Comparative psychometric three-point scaling technique was adopted with [3] attributes of same as bus fare, one and half times as bus fare and two times as the bus fare. In addition, other three attributes of speed is double, waiting time is half and comfort.

\subsection{Application of U-logit}

The sharing of the travel by public transit and personal modes depends upon the relative levels of service and the commuter behaviour of mode choice. This behaviour by individuals depends on levels of service factors like time, cost, comfort and convenience along with the reliability and dependability of the modes. The detailed investigations appropriate modelling to understand the commuter behaviour of mode choice is needed to provide the required levels of service for encouraging the public transport. It is desired to achieve a favourable split towards the mass transport, the competing capability of all other modes are to be kept in view. Keeping in view the superiority of logit model over other models like probit and discriminate analysis and in computing multi choice environment, the multinomial logit model (ULOGIT) is adopted which is developed by U.S.DOT and subsequently modified by CHARI and GUPTH for mode spilt analysis. The cross-elasticity of demand and theeffect of changes in the policy variables of one system over the patronage of others is determined by this technique [17]. The Fig 3 shows Mass Rapid Transit Desire in multi-mode environment using multinomial logit model.

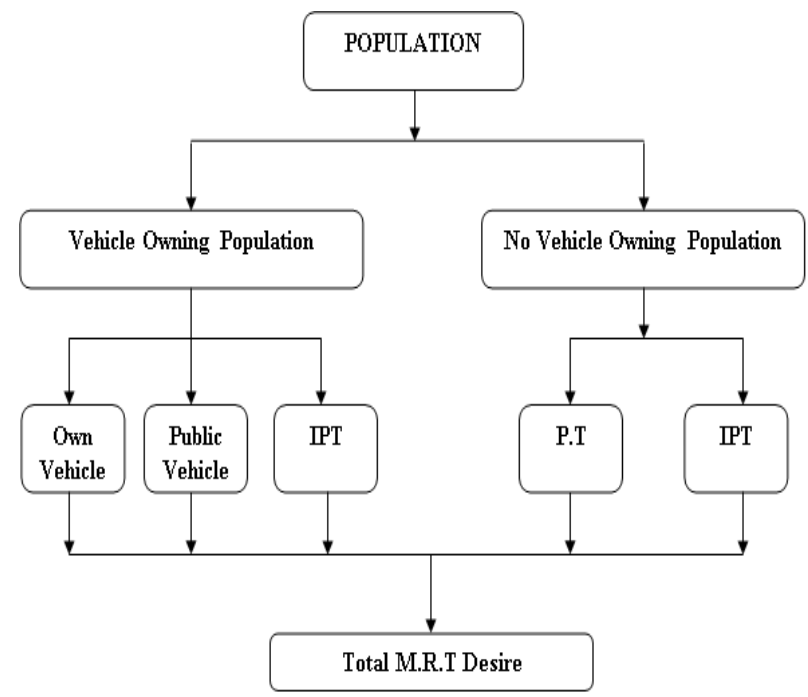

Fig. 3: Mode Choice Options for Different Classes of Population.

The data required for calibration of MULTINOMINAL LOGIT is a set of observations consisting of door to door travel time and out of pocket expresses for all modes included in the study and the mode selected for the particular trip. The data from bus passenger interview and private vehicle passenger interview are classified into two set viz., Vehicle Owing Population (VOP) and No Vehicle Population (NVP). Distances are known along the corridor, with the help of average journey speeds of various modes, the travel time is computed for each sample. Costs of travel by own vehicle (OV) i.e. cars and scooters are calculated by assuming their fuel consumption rates per kilometer as $12 \mathrm{Km} / \mathrm{liter}$ and $40 \mathrm{Km} / \mathrm{liter}$ respectively. For public transport, cost of travel is the actual ticket fare and for intermediate public transportation (IPT), the actual paid. The MRT travel time and cost are taken in term of bus travel time and cost. The dependent variable namely the probability of choosing a mode among several alternatives is a dummy variable in which the chosen mode takes a value of 1 and the next of zero. The time and cost of all the modes available for each trio, and the mode selected for the particular trips are recorded and the sample details are given to MULTINOMINAL LOGIT program.Data is prepared for VOP and as well as NVP.

Table 1: Summary of Results (Disutility Expressions)

\begin{tabular}{ll}
\hline VOG & OV $=0.0069 *$ Travel Fare- $0.0234 *$ Travel Time +26.727 \\
\hline & IPT $=0.0069 *$ Travel Fare $-0.0234 *$ Travel Time +27 \\
& BUS $=0.0069 *$ Travel Fare $-0.0234 *$ Travel Time +27.3 \\
& BUS $=0.0406 *$ Travel Fare- $0.0098 *$ Travel Time- 0.0007 Wait- \\
NVP & ing Time +30.36 \\
& IPT $=0.0406 *$ Travel Fare- $0.0098 *$ Travel Time +27.3 \\
& WALK $=-0.0098 *$ Travel Time +27.3456 \\
\hline
\end{tabular}

The disutility expressions are given in Table 1. From these expressions, probability of using MRT by different group of population is presented in Table 2 and Table 3. It is observed that the fare of metro is estimated to be twice than that of bus fare and travel time is more or less half in terms of bus. The desire of MRT system is obtained by multiplying the probability matrix by estimated OD matrix. The results are presented in Table 4 for above policy options. Also, the probability for travel cost of MRT is 1.5 times than that of bus travel cost as presented in Table5.

Table 2: Probability of Choosing MRT by VOP

\begin{tabular}{|c|c|c|c|c|c|c|c|c|c|c|c|c|c|c|c|c|c|}
\hline & 1 & 2 & 3 & 4 & 5 & 6 & 1 & 8 & 9 & 10 & 11 & 12 & 13 & 14 & 15 & 16 & 17 \\
\hline 1 & 0.64 & 0.64 & 0.63 & 0.61 & 0.61 & 061 & 0.61 & 058 & 059 & \begin{tabular}{|l|}
0.59 \\
\end{tabular} & 0.58 & 0.55 & 0.53 & 0.51 & 0.50 & 0.50 & 0.72 \\
\hline 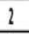 & 0.64 & 064 & 0.62 & 0.61 & 0.58 & 0.58 & 0.59 & 0.59 & 058 & 0.59 & 0.88 & 0.55 & 052 & 0.50 & 0.50 & 0.50 & 0.69 \\
\hline 3 & 063 & 0.62 & 0.64 & 0.62 & 0600 & 0.59 & 0.59 & 059 & 0.58 & 0.57 & 0.57 & 0.57 & 055 & 0.53 & \begin{tabular}{l|l|} 
\\
\end{tabular} & 0.50 & 0.68 \\
\hline 4 & 061 & 0.62 & 0.62 & 0.64 & $0.6 !$ & 061 & 0.58 & 058 & 058 & 0.57 & 0.56 & 056 & 0.56 & 0.54 & 0.54 & 0.52 & 0.68 \\
\hline 5 & 060 & 0.60 & 0.61 & 0.61 & 0.64 & 0.62 & 0.61 & 059 & 0.59 & 0.58 & 0.57 & 0.55 & 0.55 & 0.54 & \begin{tabular}{|l|}
0.54 \\
\end{tabular} & 0.53 & 0.66 \\
\hline 0 & 060 & 0.60 & 0.61 & 0.63 & 0.62 & 0.64 & 0.63 & 0.62 & 0.60 & 0.58 & 0.56 & 0.55 & 0.54 & 0.54 & 0.55 & 0.53 & 0.66 \\
\hline 1 & 058 & 060 & 0.61 & 0.61 & 0.62 & 063 & 0.64 & 0.62 & 0.60 & $\begin{array}{l}0.58 \\
\end{array}$ & 0.57 & 0.56 & 055 & 0.55 & $\begin{array}{l}0.54 \\
\end{array}$ & 0.54 & 0.65 \\
\hline 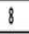 & 056 & 060 & 0.60 & 0.60 & 0.62 & 0.63 & 0.61 & 0.54 & 0.63 & 0.61 & 0.60 & 059 & 057 & 0.55 & 0.53 & 0.54 & 0.64 \\
\hline 9 & 056 & 059 & 0.60 & 0.60 & 0.61 & 062 & 0.61 & 0.62 & 0.64 & 0.62 & 0.61 & 0.58 & 058 & 0.56 & \begin{tabular}{ll|}
0.54 \\
\end{tabular} & 0.53 & 0.64 \\
\hline 10 & 057 & 058 & 0.59 & 0.60 & 0.59 & 059 & 0.61 & 0.63 & 0.62 & 0.64 & 0.2 & 0.59 & 0.56 & 0.56 & 0.54 & 0.53 & 0.62 \\
\hline 11 & 055 & 057 & 0.59 & 0.59 & 0.58 & 0.58 & 0.59 & 062 & 0.62 & 0.61 & 0.64 & 0.62 & 059 & 0.56 & 0.54 & 0.53 & 0.61 \\
\hline 12 & 052 & 0.53 & 0.58 & 0.88 & 0.57 & 056 & 0.57 & 060 & 061 & 0.61 & 0.2 & 0.64 & 062 & 0.59 & 0.56 & 0.56 & 0.60 \\
\hline 13 & 050 & 050 & 0.56 & 0.57 & 0.57 & 0.56 & 0.56 & 057 & 0.50 & 0.59 & 0.61 & 066 & 064 & 0.62 & 0.61 & 0.58 & 0.62 \\
\hline 14 & 0.48 & 0.48 & 0.53 & 0.56 & 0.55 & 0.55 & 0.56 & 0.56 & 0.58 & 0.59 & 0.59 & 0.60 & 062 & 0.64 & 0.61 & 059 & 0.60 \\
\hline 15 & 0.47 & 0.48 & 0.51 & 0.55 & 0.55 & 0.54 & 0.56 & 056 & 056 & 0.57 & 0.59 & 060 & 061 & 0.61 & 0.44 & 0.60 & 0.60 \\
\hline 16 & 0.46 & 0.48 & 0.50 & 0.54 & 0.54 & 0.53 & 0.54 & 055 & 0.55 & 0.56 & 0.55 & 0.58 & 061 & 0.61 & 0.62 & 0.54 & 0.62 \\
\hline 17 & 0.45 & 0.46 & 0.48 & 0.51 & 0.52 & 0.51 & 0.51 & 052 & 0.55 & 0.54 & 0.54 & 0.55 & 059 & 0.60 & 0.59 & 06.1 & 0.64 \\
\hline
\end{tabular}

Table 3: Probability of Choosing MRT by NVP

\begin{tabular}{|c|c|c|c|c|c|c|c|c|c|c|c|c|c|c|c|c|c|}
\hline & 1 & $l$ & 1 & 4 & 5 & 6 & 1 & 8 & 9 & 10 & 11 & 11 & 13 & 14 & 15 & 16 & 17 \\
\hline 1 & 051 & 0.48 & OAB & 0.45 & 0.45 & 0.40 & 0.46 & $O A B$ & O.H & 0.45 & $\mathrm{OAS}$ & 0.4 & 0.4 & $O A_{5}$ & 0.46 & OA9 & 0.8 \\
\hline 1 & OAB & 0.51 & OAB & 0.47 & 0.4 & 0.45 & 0.45 & 0.46 & 0.4 & 0.55 & 045 & 0.4 & 0.4 & OAB & 0.45 & 0,46 & 0.44 \\
\hline 1 & OAB & 0.48 & 0.51 & 0.48 & 0.47 & OAS & 0.45 & 0.16 & 0.6 & 0.43 & 0.45 & 0.45 & 0.45 & OAf & 0.4 & 0.15 & 10 \\
\hline 1 & 0.45 & 0.48 & 048 & 0.51 & 0.47 & 0.48 & 0.45 & 0.5 & 0.6 & 0.46 & 0.43 & OH & O.4 & OAS & 0.45 & 0.55 & 050 \\
\hline i & 0.45 & 0.45 & OQA & 0.48 & 0.51 & OAS & 0.48 & 0.65 & 0.6 & 0.45 & 045 & 0.43 & 0.44 & OAH & 0.45 & OAS & 0.8 \\
\hline 6 & 0.46 & 0.45 & $0.46^{\circ}$ & 0.48 & 0.47 & 051 & 0.48 & 0.48 & 0.5 & 0.4 & OA & 0.4 & 0.42 & 0.43 & 0.4 & OH & 0.9 \\
\hline 1 & $O A S$ & 0.46 & $\mathrm{OAO}$ & 0.46 & 0.46 & 049 & 0.59 & 048 & 0.9 & 0.4 & 244 & 0.44 & 0.4 & $\mathrm{OM}$ & 0.4 & OA. & 0.4 \\
\hline 8 & 0.43 & 0.46 & 0.46 & 0.46 & 0.46 & 046 & 0.47 & 051 & 0.8 & 0.48 & 0.45 & 0.45 & 0.45 & OA & 0.42 & 043 & 0.5 \\
\hline 1 & O.4. & 0.4 & $\mathrm{OA6}$ & 0.46 & 0.46 & $\mathrm{O}, 40$ & 0.45 & 0.97 & 0.51 & 0.48 & 049 & 0.45 & 0.45 & OAS & 0.4 & 0.42 & 0.6 \\
\hline 10 & 0.5 & 0.45 & OAH & 0.46 & 0.46 & 0.45 & 0.5 & 0.16 & 0.9 & 0.51 & 0.48 & 0.47 & 0.4 & O.4. & 0.4 & 0.4 & 0.8 \\
\hline 11 & 0.45 & 0.45 & OAS & 0.4 & 0.4 & $O A B$ & 0.4 & $046^{\circ}$ & 018 & 0.47 & 051 & 0.48 & 0.49 & OMA & 0.4 & 0.4 & 0,5 \\
\hline 12 & 0.4 & 0.4 & 0.5 & 0.45 & 0.4 & 0.43 & 0.45 & 0.15 & 0.6 & 0.45 & Q497 & 0.51 & 0.48 & 0.97 & 0.55 & 0.55 & 0.6 \\
\hline 13 & OAL & O.4 & 0,45 & 0.45 & 0.4 & 0.13 & 0.43 & 0.5 & 0.6 & 0.44 & 045 & 0.47 & 0.51 & OAS & 0.48 & OAS & 0.6 \\
\hline 11 & OA. & 0.4 & 0.45 & 0.45 & 0.45 & 0,43 & 0,43 & 0.43 & 0.5 & 0.55 & OHA & 0.45 & 0.47 & 059 & 0.88 & 0.97 & 0.6 \\
\hline 15 & 046 & 0.45 & $\mathrm{OAS}$ & 0.45 & D.4. & $\mathrm{OAH}$ & D. & $Q, 13$ & 0.8 & 0.45 & 0.55 & 0.46 & 0.46 & OAS & 0.51 & DQ97) & 0.9 \\
\hline 16 & 0.65 & 0.46 & 0.45 & 0.66 & 0.66 & O.4. & D. & O.4 & 0.8 & 0.43 & 0.55 & 0.45 & 0.66 & 0.60 & 0.15 & 0.51 & 0.8 \\
\hline 11 & $O A B$ & 0.46 & $\mathrm{OA6}$ & 0.46 & 0.45 & OU. & 0.43 & 0,13 & 0.4 & 0.43 & 0.43 & 0.45 & 0.45 & $\mathrm{OAO}$ & 0,45 & 0.5 & 0.54 \\
\hline
\end{tabular}


Table 4: Corridor Level MRT Passenger Trip Matrix (MRT Cost Is 2 Times That of Bus)

\begin{tabular}{|c|c|c|c|c|c|c|c|c|c|c|c|c|c|c|c|c|c|}
\hline & 1 & l & 3 & 4 & 5 & 6 & 1 & 8 & 9 & 10 & 11 & 12 & 13 & 14 & 15 & 16 & 17 \\
\hline 1 & 0 & 4116 & 5319 & 2983 & 3312 & 3300 & 17675 & 5192 & 440 & 3344 & 522 & 5513 & 035 & 254 & 956 & 992 & 4795 \\
\hline l & 451 & 0 & 476 & 3154 & 2766 & 2724 & 5035 & 14883 & 662 & 436 & 2213 & 266. & 150 & 836 & 373 & 334 & 7.23 \\
\hline 3 & 1158 & 1018 & 0 & 15745 & 1594 & 562 & 4334 & 8815 & 5974 & 839 & 447 & 5991 & 2884 & 296 & 1573 & 8689 & 1523 \\
\hline 4 & 327 & 36.4 & 351 & 0 & 376 & 6435 & 5106 & 974 & 13922 & 952 & 1777 & 1888 & 336 & 54 & 516 & 8 & 225. \\
\hline 5 & 5. & 5867 & 1031 & 8102 & 0 & 4530 & 17670 & 750 & 5183 & 2015 & 2008 & 552 & 740 & 2013 & 708 & 1717 & 2832 \\
\hline 6 & 2218 & 1955 & 32.1 & 367 & 1524 & 0 & 82658 & 12218 & 2594 & 932 & 50 & 788 & 255 & 44 & 163 & 332 & 600 \\
\hline 1 & 80 & 1116 & 1.46 & 2886 & 18 & 19579 & 0 & 480 & 10079 & 1740 & 8137 & 12120 & 459 & 2129 & 3300 & 8891 & 12460 \\
\hline 8 & 9.15 & 1330 & 980 & 1701 & 138 & 2815 & 1.155 & 0 & 1499 & 433 & 1518 & 43372 & 8387 & 1084 & 300 & 11022 & 1958 \\
\hline 9 & 920 & 899 & 1265 & 2214 & 1472 & 648 & 345 & 3265 & 0 & 1332 & 15352 & 19119 & 8837 & 3608 & 502 & 15416 & 284 \\
\hline 10 & 838 & 2652 & 2991 & 36888 & 372 & 8726 & 5339 & 321 & 11251 & 0 & 18835 & 372 & 17980 & 4285 & 12855 & 769 & 633 \\
\hline 11 & 3385 & 1998 & 3204 & 149 & 315.2 & 4785 & 7033 & 9765 & 12313 & 64.18 & 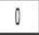 & 6731 & 1019 & 800 & 740 & 18881 & 2657 \\
\hline 12 & Wut & 2012 & 2610 & 1749 & 3280 & 6620 & 653 & 5808 & 15769 & 8240 & 10088 & 0 & 93 & 2499 & 26.76 & 7512 & 64111 \\
\hline$B$ & 399. & 4746 & 4786 & 9580 & 490 & 7800 & 9381 & 782 & 13505 & 15280 & 1395 & 466. & 0 & 15317 & 712 & 28865 & 863.1 \\
\hline 14 & 7524 & 3333 & 1074 & 12.54 & 15158 & 1872 & 57213 & 3259 & 3994 & 3350 & 48552 & 78991 & 1577 & 0 & 4014 & 15533 & 2814 \\
\hline 15 & 617) & 282 & 207 & 88 & 986 & 1184 & 245 & 236 & 1985 & 3678 & 2060 & 1045 & 5887 & 870 & 0 & 3331 & 6339 \\
\hline 16 & 7966 & 3797 & 1734 & 1007 & 1077 & 1044 & 25899 & 2004 & 1357 & 770 & 10534 & 27978 & 60030 & 31.34 & 1838 & 0 & 10320 \\
\hline 17 & 4359 & 2147 & 142 & $\pi T$ & 788 & 395 & 515 & 1885 & 10815 & 12836 & 3065 & 3353 & 3897 & 13958 & 102811 & 11870 & \\
\hline
\end{tabular}

Table 5: Corridor Level MRT Passenger Trip Matrix (MRT Cost Is 1.5 Times That of Bus)

\begin{tabular}{|c|c|c|c|c|c|c|c|c|c|c|c|c|c|c|c|c|c|}
\hline & 1 & l & 3 & 4 & j & 0 & 1 & 8 & 9 & 10 & 11 & 12 & 13 & 4 & 15 & 16 & 17 \\
\hline 1 & 0 & 4.83 & 5380 & 30.3 & 3.15 & 242 & 17909 & 5391 & 543 & 4076 & 549 & 5559 & 915 & 2304 & 97 & 4.13 & 15135 \\
\hline l & 59 & 0 & 4533 & 305 & 2559 & 2813 & 51566 & 1597 & 640 & 450 & 2655 & 2216 & 40 & 856 & 3212 & 387 & 13212 \\
\hline 3 & 1072 & 1035 & 0 & 10015 & 1798 & 520 & 45777 & 8881 & 608 & 91.8 & 4555 & 6036 & 30 & 2998 & 1711 & 8887 & 1578 \\
\hline 4 & 3740 & 3661 & 3307 & 0 & 3833 & 621 & 52713 & 1006 & 14.18 & 978 & 1817 & 1874 & 375 & 610) & $2 / 1$ & 29 & 2266 \\
\hline 5 & 52 & 6033 & 1.569 & 844 & 0 & 46212 & 17975 & 7763 & 5551 & 2033 & 2047 & 437 & 759 & 2.27 & 727 & 1754 & 2876 \\
\hline 6 & 2156 & 2028 & 3527 & 309 & 16680 & 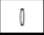 & 8301. & 1265 & $6 \pi 7$ & 98 & 602 & 783 & 260 & 45 & 158 & 341 & 60 \\
\hline 1 & 87 & 1136 & 1400 & 2587 & 153 & 20079 & 0 & 4750 & 10215 & 1804 & 8723 & 18373 & 4.4 & 13326 & 347 & 9125 & 1274 \\
\hline 8 & $\pi t$ & 1355 & 1007 & 1755 & 140 & 9 & W & 0 & $14+40$ & 4.53. & 19882 & 4773 & 6011 & 11061 & 3847 & 11312 & 20004 \\
\hline 9 & 913 & 933 & 1288 & 254 & 15.8 & 6233 & 3520 & 36.18 & 0 & 1456 & 15557 & 1975 & 864 & 23523 & 531. & 17116 & 2068 \\
\hline 10 & 245 & 230 & 3110 & 3753 & 3790 & 9018 & 5775 & 3317 & 1150 & 0 & 1727 & 3814 & 1599 & $4: 699$ & 13232 & 7647 & 500 \\
\hline 11 & 366 & 2046 & 3278 & 1972 & 3274 & 487 & 7325 & 10060 & 1265 & 27112 & 0 & 66537 & 1445 & 2020 & 7688 & 1900 & 2269 \\
\hline 12 & 2009 & 265 & 2673 & 1790 & 31.17 & 8850 & 6070 & 6074 & 15255 & 897 & 11991 & 0 & 939 & 25013 & 2346. & $\pi 71$ & 4199 \\
\hline$B$ & 390 & 455 & 4966 & 981.1 & 5001 & 8116 & 9756 & 7932 & 1392 & 15755 & 14229 & 4855 & 0 & 1655 & 721 & 21550 & 8364 \\
\hline A & 7705 & $3 / 13$ & 1059 & 12764 & 1556 & 1999 & 5982 & 3566 & 0772 & 4038 & 50045 & 8909 & 1720 & 0 & 48.4 & 1578 & 20166 \\
\hline 15 & 62 & 299 & 211 & 90 & 1022 & 1215 & 2975 & 38 & 1649 & 3750 & 2127 & 1078 & 5759 & 9.62 & 0 & 5371. & 6457 \\
\hline 16 & 826 & 3060 & 1774 & 1208 & 19939 & 10832 & 26336 & 2655 & 14003 & 8078 & 111178 & 2838 & 60009 & 3003 & 1928 & 0 & 106890 \\
\hline 17 & 494 & 2332 & 1497 & 796 & 7968 & 3993 & 537 & 1937 & 11098 & 13389 & 31757 & 3019 & 35009 & 4532 & 10576 & 124.20 & 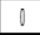 \\
\hline
\end{tabular}

\section{Summary and conclusions}

Thevast vehicular population growth results in limited right of way, overcrowding, accidents, insufficient parking and environmental deterioration, the challenging issues for Hyderabad city. To resolve the above issues, MRT system is essential. To propose such arrangement, there is a need to find the demand for the proposed MRT. The data collected through primary survey are traffic volume counts, bus boarding and alighting counts and passenger interview survey with stated preference.

The multi nominal logit (ULOGIT) is used to bring out the disutility expression. Finally, probability matrices multiplied by various population groups by various modes are achieved. These zone-to-zone desires are assigned on the corridor. Thus, MRT travel desire is obtained.

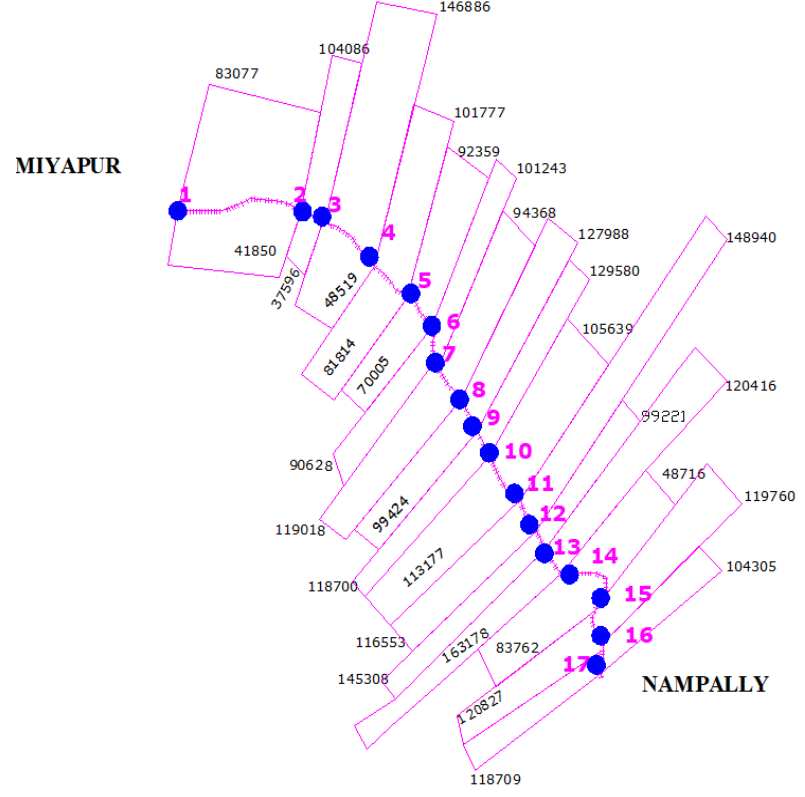

Fig. 4: Section Loads on MRT Network.

Following are the conclusions drawn from the current study

- From the past study of Hyderabad city, one can observe that Miyapur to Nampally is one of the major corridors.

- Estimation of corridor level O-D matrix from traffic counts is reliable than that of conventional models.

- From the traffic counts, one can observe that the public passengers' mode share is $46 \%$, but ideal public mode share is $75 \%$. To achieve this share, public mode transport should be encouraged.

- $\quad$ ULOGIT model brought out the disutility expressions, which is used to estimate the probability of choosing the MRT.

- As patronage estimated, it is recommendable for the MRT system.

\section{References}

[1] Advani M \&Tiwari G (2005), Evaluation of Public Transport Systems: Case Study of Delhi Metro.Transportation Research \& Injury Prevention Programme, Proceeding in START-2005 Conference held at IIT Kharagpur, India.

[2] AnilA (2005), Estimation of Passenger Travel Demand for Chennai. START 2005 Conference Report, IITKharagpur, 646-652.

[3] Anisuddin S (1998), Mass Transit System Planning and Scheduling for an Identified Corridor in Corporatingon-line Congestion Effects through Optimization Techniques.Phd Thesis Report, REC, Warangal

[4] AshleyDJ, Forecasting Passenger Travel Demand- International Aspects. Transportation Research Board, 14, 147-157.

[5] Bruce TW,The Wisconsin Multi-Modal Intercity Passenger Demand Forecasts.

[6] Boyce D, Lupa M, \&Zhang YF (1994), Introducing "Feedback" into the Four-Step Travel Forecasting Procedure vs. the Equilibrium Solution of a Combined Model.73rd Annual Meeting of Transportation Research Board.

[7] Caldas MA,\& Black IG (1997), Formulating A Methodology for Modeling Revealed Preference Discrete Choice Data-The Selectively.Transportation Research Board, 31 (6), 463-472.

[8] Chari S D (1997), Estimation of Public Transit Demand for A Shortest Root Identified by Hamilttonian Cycle Program in Hyderabad City.M.Tech Thesis Report, REC, Warangal.

[9] DhingraSL (2005), Master Plan for Metro Project. START 2005 Conference Report, IITKharagpur, 119-132.

[10] Fillone M, Credence MM, \&Noriel CC (2007), Transport Mode Choice Models For Metro Manila and Urban Transport Policy Applications.Journal of the Eastern Asia Society for Transportation Studies, 7.

[11] Gan C \&Clemes M (2006), Alogit analysis of electronic banking in NewZealand. International Journal of Bank Marketing, 24 (6), 360383. 
[12] HensherDA, \& RoseJM (2007), Development of Commuter and noncommuter mode choice models for the assessment of new public transport infra structure projects: A Case study. Transport Research part $a, 41,428-443$.

[13] Hironoro K, YuichiroK, \&Masahi I, Choice of travel demand forecast models: comparative analysis in urban rail route choice.Department of civil engineer, University of Tokyo.

[14] Kato H, Kaneko Y, \& Inoue M (1984), Choice Of Travel Demand Forecast Models: Comparative Analysis In Urban Rail Route Choice.Transportation Research Board, 415, 289-299.

[15] NairVC, \&UdayaKumarR(2008),Traffic congestion-Consequences and Mitigative measures. Proceedings of the International Conference on BPRCM, IITM Chennai, 3-11.

[16] PengpengJ,Huapu LU, \& Lang Y (2006),Disaggregate traffic mode choice model based on combination of revealed and stated preference data.Tsinghua Science and Technology,11 (3),351-356.

[17] Rama Moorthy N V (1996), Planning of Integrated Transit Network for Bus and LRT. Journal of Advanced Transportation, 31 (3), 283306.

[18] Reddy an M (1995), Estimation of Patronage on the proposed LRT system in Hyderabad through corridor Analysis.M.Tech Thesis Reoprt, REC, Warangal.

[19] SpielbergF,HitlinRA, BarberE, \&AndrleS(1987), Estimating Small Area Public Transit Use by Direct Survey. Transportation Research Record 1144, 41-46.

[20] ShepherdLE(1972), An Econometric Approach to the Travel Demand for Urban Passenger Travel. ARRB Proceedings, Vol.6, Part 2.

[21] SikdarPK (2004), Modelling and Analysis Forecasting of Ridership of Delhi Metro. Central Road Research Institute, New Delhi.

[22] Yao E \& Mori T (2005), A Study of an integrated intercity travel demand model. Transport Research part a, 39, 367-381. 